
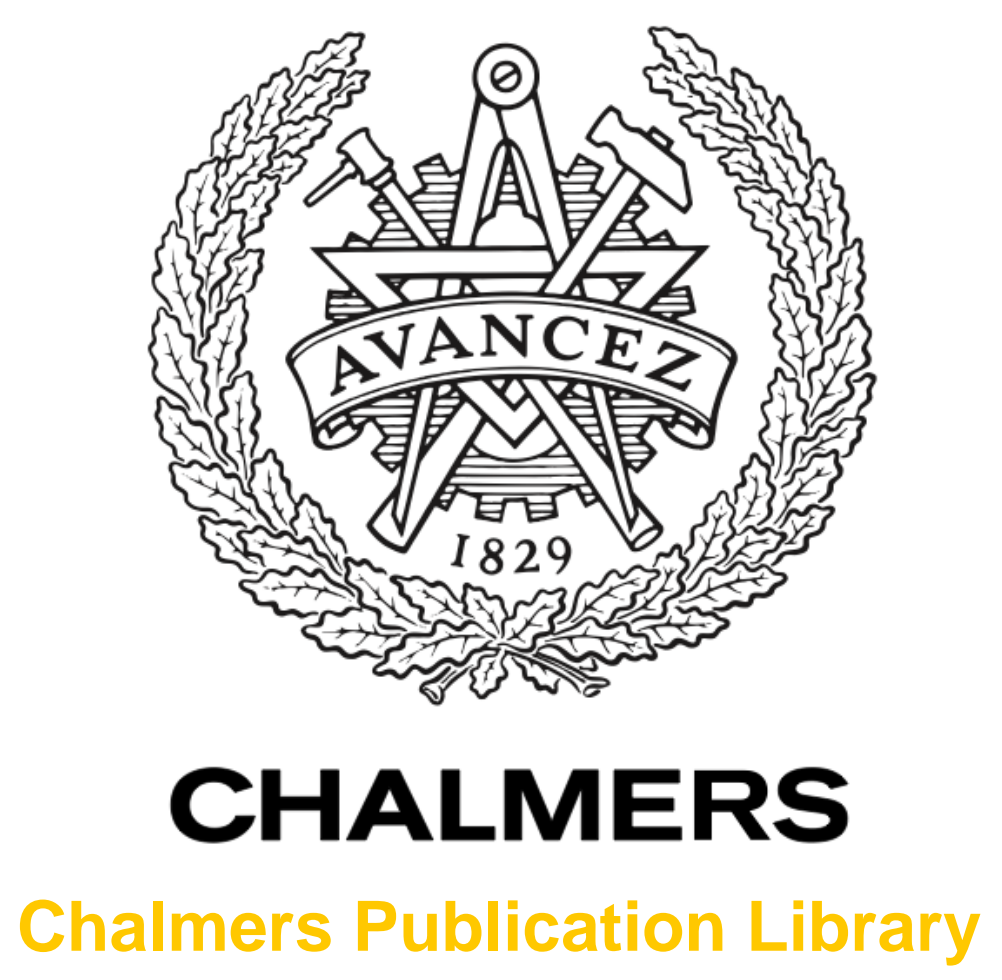

Impact of melt rheology on zein foam properties

This document has been downloaded from Chalmers Publication Library (CPL). It is the author's version of a work that was accepted for publication in:

Journal of Materials Science (ISSN: 0022-2461)

Citation for the published paper:

Gillgren, T. ; Alven, T. ; Stading, M. (2010) "Impact of melt rheology on zein foam properties". Journal of Materials Science, vol. 45(21), pp. 5762-5768.

http://dx.doi.org/10.1007/s10853-010-4649-3

Downloaded from: http://publications.lib.chalmers.se/publication/127123

Notice: Changes introduced as a result of publishing processes such as copy-editing and formatting may not be reflected in this document. For a definitive version of this work, please refer to the published source. Please note that access to the published version might require a subscription. 


\title{
Impact of Melt Rheology on Zein Foam Properties
}

\author{
Thomas Gillgren ${ }^{a}$, Tommy Alvén ${ }^{a}$ and Mats Stading ${ }^{a, b^{*}}$
}

\begin{abstract}
Zein, the main protein fraction in maize, is left as a by-product from bio-ethanol production. The protein has been investigated as a material for a long time, but mainly in the form of films. In contrast, foamed zein is presented in this paper. Zein foams may perhaps be used e.g. as trays for biodegradable food packages or as scaffolds for tissue engineering. A batch method for manufacturing solid foams was successfully developed, the foams being manufactured by evaporation of solvent from zein resins. In order to be suitable for foam formation, a resin must possess gas-retaining properties, which can be predicted by extensional rheology. The presence of plasticizer in some of the resins decreased their extensional viscosity, and this in turn affected the foaming process. Although all the resins displayed strain-hardening behaviour, there was coalescence of pores in all the foams. Insufficient extensional viscosity resulted in the collapse of pore walls during foam expansion. Structure analysis showed e.g. that most pores were elongated along the main axis of the mould in which the foams were manufactured. The plasticizer content in the resins had no significant effect on the mechanical properties of the foams.
\end{abstract}

\section{Key Words}

Zein, biopolymer, biodegradable, foam, rheology

\section{Introduction}

Large amounts of petroleum are currently being used for disposables, packages and fuel. This runs counter to an environment- and climate-friendly development, as petroleum is not a renewable resource. One alternative to petroleum-based fuel is bio-ethanol made from cereals. In the production of such biofuels, only the starch of the cereals is consumed, leaving cereal proteins such as prolamins as byproducts. In the U.S., ethanol biofuel is predominantly manufactured from maize starch, and hence the maize prolamin zein is left available. Zein has long been recognized as a potential resource ${ }^{1}$, and zein also possesses properties making it suitable for biomedical applications, such as resorbable implants. ${ }^{2-6}$ Many synthetic bioresorbable polymer materials suffer from problems due to degradation products which increase the acute inflammatory response. ${ }^{7}$ According to Sun et al. ${ }^{2}$ the degradation products of zein are not cytotoxic, but rather increase the cell viability. For these reasons, zein is obviously an exciting material.

Materials manufactured from zein have been extensively investigated and reported on. However, these reports and investigations have almost exclusively dealt with materials in the shape of films. In the present project, foamed zein is studied in contrast to previous studies. The few papers on foamed zein that do exist use the salt leaching method ${ }^{3,6,8}$ or over-saturation of $\mathrm{CO}_{2}$ and $\mathrm{N}_{2}$ by pressurization ${ }^{9}$ to manufacture foams. An adjacent area is bread-baking, in which foams are formed from biopolymers (gluten and starch). Dobraszczyk and Roberts ${ }^{10}$ have investigated the impact of extensional rheology on bread-baking properties.

Intuitively it can be understood that gas-retaining properties are crucial if a resin is to be foamable. For Newtonian liquids, rupture of the filaments (cell walls) depends on the surface tension. However,

*Correspondence to: Mats Stading, SIK, Box 5401, SE-402 29 Gothenburg, Sweden. E-mail: mats.stading@sik.se a: SIK - The Swedish Institute for Food and Biotechnology, Gothenburg, Sweden.

b: Chalmers University of Technology, Gothenburg, Sweden. 
zein resins are viscoelastic fluids, and the rupture is accordingly more dependent on properties that can be evaluated by rheological measurements. ${ }^{11,12}$ During foam formation, gas cells grow through biaxial extension at high strains and usually low extension rates. ${ }^{10,12}$ Low viscosity is necessary for bubble nucleation but, on the other hand, there is a lower viscosity limit below which the cell walls collapse during cell expansion. This, of course, causes failure of the foaming process. Gas retention is also dependent on the strain-hardening properties of the resin. ${ }^{10,12,13}$ Strain-hardening reduces the localized deformation in thinner parts of a pore wall owing to a stress increase, and the prevents coalescence of cells. Extensional viscosity measurements of the resin material can show whether it fulfils the requirements for foaming. The Hyperbolic Contraction Flow method was used in the present work.

In this investigation, a batch process was used for the manufacture of solid zein foams; zein resins were prepared, rheologically analyzed and foamed by solvent evaporation. The foams where then characterized with respect to their mechanical properties, structure and density. The results show how the foam properties were affected by the rheological properties of the zein resin, which in turn were controlled by the plasticizer content

\section{Experimental}

\section{Resin and Foam Formation}

Commercial zein (Z3625; Sigma-Aldrich, Schnelldorf, Germany) was defatted in n-hexane as described by Oom et al. ${ }^{14}$ The protein content of the zein was $92 \%(w / w)$, determined using the Dumas method and multiplying the nitrogen content by 6.25. Zein resins were then prepared by mixing $3.0 \mathrm{~g}$ (dry weight) of zein powder with oleic acid (as plasticizer, $0 \%$; $5 \%$; $10 \%$ and $30 \%$, w/w) and $1.05 \mathrm{~g}$ aqueous ethanol ( $70 \% \mathrm{w} / \mathrm{w})$. The mixtures were kneaded by hand for approximately one minute until resins were formed. The zein resin was then placed in a mould, consisting of an aluminium block (width $62 \mathrm{~mm}$, length $62 \mathrm{~mm}$, height $80 \mathrm{~mm}$ ) with a vertically orientated cylindrical hole (20 mm diameter). The mould containing the resin was kept in an oven at $175^{\circ} \mathrm{C}$ for 20 minutes, and the block with the newly formed foam was then allowed to cool.

\section{Dynamic Measurements}

Dynamic measurements in small amplitude oscillatory shear were performed as described by Oom et al. ${ }^{14}$ using a Stresstech HR Rheometer (Rheologica Instruments, Lund, Sweden) equipped with parallel plates $15 \mathrm{~mm}$ in diameter. Samples were placed between the plates with a gap of $3 \mathrm{~mm}$ and the periphery of the sample was covered with paraffin oil to prevent evaporation and oxidation. The linear region was first determined by a stress sweep from 1 to $1000 \mathrm{~Pa}$ at $1 \mathrm{~Hz}$. Thereafter, a frequency sweep from 0.01 to $10 \mathrm{~Hz}$ at the chosen stress, within the linear region identified in the stress sweep, was performed on fresh samples. The Cox-Merz' rule was applied and data were fitted to the power-law model for shear flow to obtain the power-law index $\mathrm{n}$ and constant $\mathrm{K}$ needed for evaluation of the Hyperbolic Contraction Flow measurements. The studies were performed at room temperature and replicated three times.

\section{Hyperbolic Contraction Flow}

The extensional rheological properties of the resins were measured as described by Oom et al. ${ }^{14}$ using a Hyperbolic Contraction Flow rig ${ }^{15,16}$ mounted in an Instron 5542 Universal Testing Instrument (Instron Corporation, Canton, USA). The extensional strain rates used were $0.1 \mathrm{~s}^{-1}, 0.7 \mathrm{~s}^{-1}, 1.2 \mathrm{~s}^{-1}$ and $2.2 \mathrm{~s}^{-1}$ as described by Wikström and Bohlin ${ }^{15}$. Due to ageing of the resins, the same sample was never used for more than one measurement. The transient extensional stress was monitored until a stable plateau value was reached from which the maximum extensional viscosity was calculated. The different Power-law parameters acquired in the dynamic measurements were used to compensate for the shear stress 
contribution to the total stress. The shear contribution was small in all cases ( $\sim \%$ ). Measurements were performed at room temperature and each test was replicated three times.

\section{Structure Analysis}

Five foam samples with each plasticizer content were cleaved in two and scanned with a CanoScan N1240U scanner (Canon Inc., Tokyo, Japan) using 2400 dpi resolution. The images were binarized and analyzed with AnalySIS software (Soft Imaging System GmbH, Germany), with respect to the star volume $\left(V_{v}\right)$, surface density $\left(S_{v}\right)$, area, orientation, aspect ratio, convexity and sphericity of the pores. A threshold of 50 pixels was used to eliminate bias from noise during the detection. Star volume and surface density were measured according to Weibe $^{17}$ and Cruz-Orive ${ }^{18}$, where a mesh of regular chords with 128 pixels spacing and $0^{\circ}, 30^{\circ}, 60^{\circ}$ and $90^{\circ}$ angle were applied across the binarized images. The star volume was calculated according to

$V_{v}=\frac{\pi}{3} \bar{l}_{0}^{3}$

where $\bar{l}_{0}^{3}$ is the mean of the cubes of the lengths of the parts of the applied chords that overlap the pores. The surface density was calculated according to

$$
S_{v}=2 \frac{n}{l_{\text {tot }}}
$$

where $n$ is the number of intercepts between a chord and the phase border between a pore and the surrounding matrix, and $l_{\text {tot }}$ is the total length of the chords overlapping both of the phases. The ratio of the accumulated area of the larger pores (which were assumed to be coalesced) to the total area of all pores was calculated and denoted $A_{I} / A_{\text {tot }}$. To analyze cell orientation data, the cells were sorted into eight different categories according to their orientation: $\left(0^{\circ}+n \cdot 22.5^{\circ}\right) \pm 11.5^{\circ}$, where $n$ is an integer between 0 and 7 .

\section{Density and mechanical properties}

To determine the density of the foams, the sample weight was recorded and divided by the sample volume, calculated from the cylinder diameter and sample height. To study the fracture mechanics of the foams, samples with a height at least equal to the diameter were compressed in an Instron 5542 singlecolumn universal materials testing machine (Instron, Norwood, MA, USA). All the samples were conditioned at $23{ }^{\circ} \mathrm{C}$ and $50 \%$ relative humidity (RH) for at least $48 \mathrm{~h}$ before testing. Tests were replicated at least four times. The testing speed was set to $2.1 \mathrm{~mm} / \mathrm{min}$. The instrument recorded force and strain $(\varepsilon)$, and the compressive stress $(\sigma)$ was calculated from the force and the sample dimensions. A stress vs. strain plot displayed three regions: a continuous slope up to the peak where the foam first started to break, a jagged part where the cell walls collapsed, and finally a densification part where the curve showed a steadily increasing stress due to densification of the foam fragments. The Young's modulus was defined as the slope of the first part of the curve. The area below the second part yielded the energy absorbed $(W)$ during compression, and was calculated according to

$$
W=\int_{\varepsilon_{c}}^{\varepsilon_{d}} \sigma(\varepsilon) d \varepsilon
$$

where $\varepsilon_{c}$ represents the start of the second region, and $\varepsilon_{d}$ is the point where the densification (third) region starts. The strain at break and the stress at break were defined as the strain and the stress at the point $\varepsilon_{c}$. 


\section{Statistical analysis}

The $95 \%$ level of confidence was used through-out the investigation. Pair-wise one-way ANOVA-tests with Tukey error protection were used to compare samples. The significance is generally denoted by superscript letters in the tables. Values followed by the same letter in the same column/row are not significantly different $(\mathrm{P}<0.05)$.

\section{Results and Discussions}

Rheology

The extensional viscosity of the zein resins was defined as the horizontal plateau (Fig. 1). The trend was for increasing plasticizer content to lead to a decrease in extensional viscosity (Fig. 2). In addition, there is a slight strain-thinning behaviour, which however is most evident at lower plasticizer contents.

Results obtained at $2.2 \mathrm{~s}^{-1}$ strain rate seem to be diverging; probably because these were obtained from a different defatted zein batch. The results are all in accordance with those reported by Oom et al. ${ }^{14}$, about $300 \mathrm{kPas}$ at strain rates $0.74 \mathrm{~s}^{-1}-2.98 \mathrm{~s}^{-1}$ for oleic-acid-plasticized zein resins, and also with results for zein/starch resins $\left(\sim 200 \mathrm{kPas}\right.$ at $\left.0.55 \mathrm{~s}^{-1}-2.19 \mathrm{~s}^{-1}\right)$ reported by Andersson et al. ${ }^{19}$

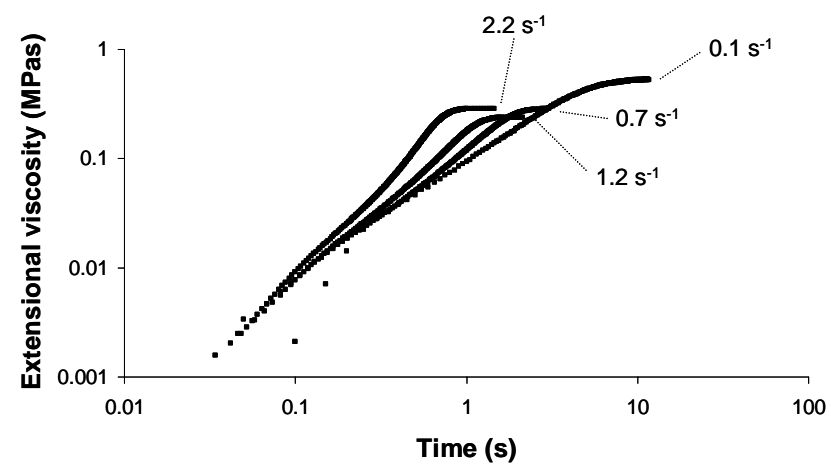

Figure 1. The raw data for the Hyperbolic Contraction Flow measurements at different strain rates on unplasticized zein resins.

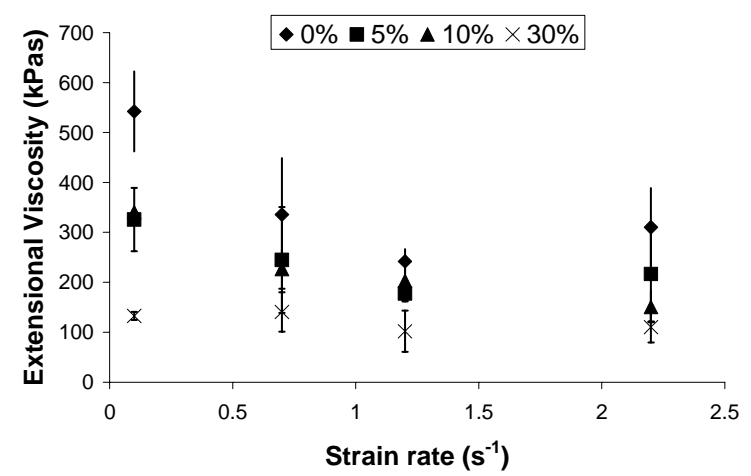

Figure 2. Extensional viscosity of resins with $0 \%$ (diamonds), $5 \%$ (squares), $10 \%$ (triangles) and $30 \%$ (crosses) plasticizer content. Error bars indicate the $95 \%$ level of confidence.

The strain-hardening index was calculated as the slope of a line fitted by a power law relationship to the log-log-plot of the viscosity growth data obtained by contraction flow measurements (Fig. 1). Fig. 3 shows that the strain-hardening index was above 1 for all the resins at all strain rates, except for the plasticized resins at the lowest strain rate. This implies that the resins are strain hardening, which is a 
crucial quality for foam manufacturing according to. ${ }^{10,12}$ The values presented here are lower than those reported by Oom et al. ${ }^{14}\left(1.9-3.2\right.$ at strain rates between $0.74 \mathrm{~s}^{-1}$ and $\left.2.98 \mathrm{~s}^{-1}\right)$. However, the results are of the same order of magnitude, and the differences may well be explained by the different resin manufacturing methods. The results reported by Andersson et al. ${ }^{19}\left(0.9-1.86\right.$ at $\left.0.55 \mathrm{~s}^{-1}-2.19 \mathrm{~s}^{-1}\right)$ are also in agreement with those presented here. The extensional strain rate in the current foaming process was not determined, and is hard to estimate. According to Dobraszczyk and Morgenstern ${ }^{20}$, the expansion of (bread) dough in an oven corresponds to extensional strain rates of $0.0005 \mathrm{~s}^{-1}$ to $0.005 \mathrm{~s}^{-1}$. The foaming process in the current investigation is probably quicker with higher extensional strain rates.

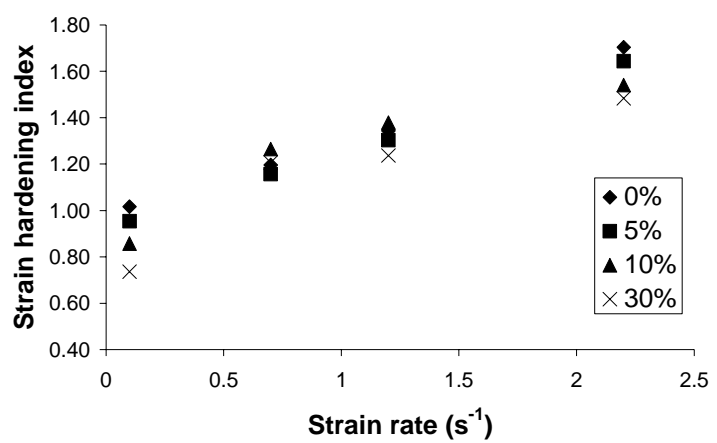

Figure 3. Strain-hardening index of resins with $0 \%$ (diamonds), $5 \%$ (squares), $10 \%$ (triangles) and $30 \%$ (crosses) plasticizer content.

The extensional rheology was measured at room temperature. Although foaming took place at elevated temperatures, the resins could not for technical reasons be rheologically evaluated at those temperatures. It is nevertheless probable that the patterns observed at room temperature are also valid at the elevated temperatures prevailing during the foaming process.

\section{Structure}

Fig. 4 indicates that the addition of plasticizer gave rise to a more irregular structure and larger pores. The sample based on the $30 \%$ plasticizer resin was not really foam, but merely an empty shell with slightly porous walls. Hence, these samples will not be considered in any further foam analysis. The pore structures of the $0 \%, 5 \%$ and $10 \%$ plasticizer foams can be described as semi-open since some pores were interconnected while others remained isolated.
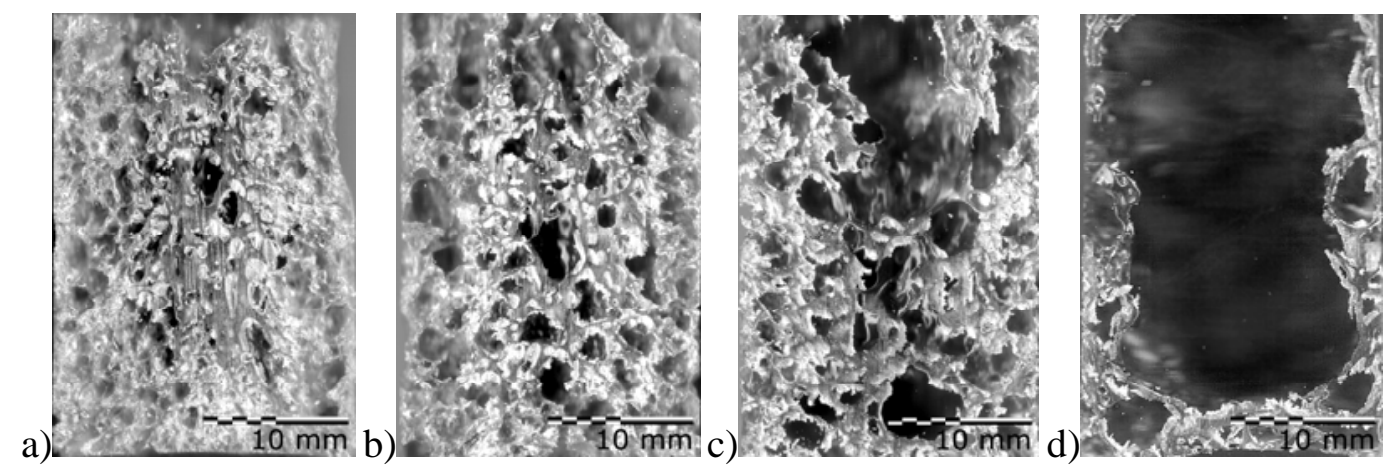

Figure 4. Foams from resins containing a) $0 \%$; b) $5 \%$; c) $10 \%$ and d) $30 \%$ plasticizer.

Fig. 5 shows the distribution of directions of the pore orientation. The orientation was measured between $0^{\circ}$ and $180^{\circ}$, where $0^{\circ}$ (and $180^{\circ}$ ) is parallel to the main axis of the mould. The angles were 
divided into eight different intervals, constituting eight different main directions. There was no indication of any significant difference between the foams with different plasticizer contents. The most common direction (which was also statistically significant) was along the main axis of the mould. This can mean that the expansion of the resin could mainly take place in one direction due to the geometry of the mould. There was also a slight but significant intensification in pores with a radial orientation $\left(90^{\circ}\right)$. When a fluid is moving through a cylinder along the main axis under a constant pressure, the velocity will be highest in the middle of the cylinder due to friction along the cylinder walls. As the flow profile collapses at the top of the liquid, owing to gravity, there will be a radial flow. This may have caused the radially oriented pores.
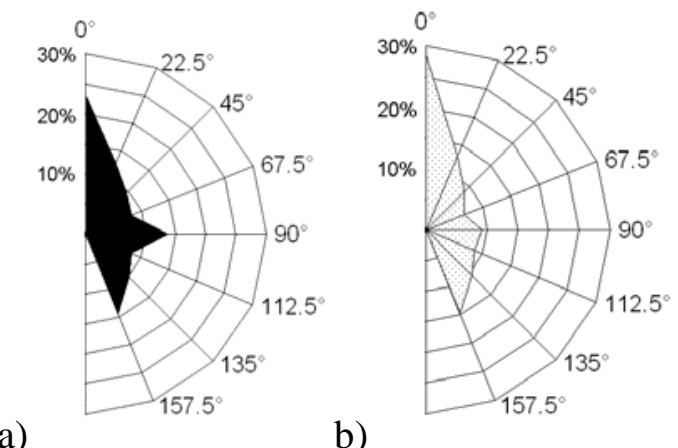

b)

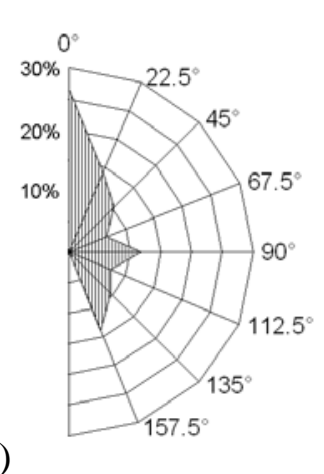

c)

Figure 5. Pore angle distribution of foams from resins with a) $0 \%$, b) $5 \%$ and c) $10 \%$ plasticizer. Mean percentage of pore orientation, categorized in eight directions $\pm 11.25^{\circ}$.

Results in Table 1 show that the mean convexity and aspect ratio of the pores in the $0 \%, 5 \%$ and $10 \%$ plasticizer foams were insignificantly different, i.e. the pores in all the foams were generally slightly convex and moderately elongated. The pore size distribution data (not shown) of the foams revealed that most pores were relatively small and that there was a sharp drop in the number of pores with sizes around $0.02 \mathrm{~mm}^{2}$ and above; $72-79 \%$ of the pores in all the foams had sizes between 0.0058 $\mathrm{mm}^{2}$ and $0.02 \mathrm{~mm}^{2}$. The rest of the pore sizes were relatively evenly distributed up to $\sim 400 \mathrm{~mm}^{2}$. The observed pore size threshold of $0.02 \mathrm{~mm}^{2}$ may indicate that this was a general limit for typical pores, and that larger pores were the result of coalescence. Table 1 shows that an increase in plasticizer content tended to increase the accumulated area of the larger pores $\left(\geq 0.02 \mathrm{~mm}^{2}\right)$ compared to the total area of all pores $\left(A_{L} / A_{t o t}\right)$, indicating that an increase in plasticizer content tended to increase the coalescence of the pores during foam formation.

Table 1. Mean convexity, aspect ratio, star volume $\left(V_{v}\right)$, surface density $\left(S_{v}\right)$ and pore area ratio $\left(A_{L} / A_{t o t}\right)$ of foams from $0 \%, 5 \%$ and $10 \%$ plasticizer resins. The pore area ratio was calculated as the accumulated area of the larger pores $\left(\geq 0.02 \mathrm{~mm}^{2}\right)$ divided by the total pore area of the foam. Values followed by the same letter in the same column are not significantly different $(\mathrm{P}<0.05)$.

\begin{tabular}{l|ccrrr}
\hline Sample & Convexity & Aspect ratio & $V_{V}\left(\mathrm{~mm}^{3}\right)$ & $S_{V}\left(\mathrm{~mm}^{-1}\right)$ & \multicolumn{1}{c}{$A_{L} / A_{\text {tot }}$} \\
\hline $0 \%$ & 0.92 & 1.55 & $3.40^{\mathrm{a}}$ & $3.36^{\mathrm{a}}$ & $94.2 \%^{\mathrm{a}}$ \\
$5 \%$ & 0.92 & 1.55 & $8.22^{\mathrm{a}, \mathrm{b}}$ & $2.85^{\mathrm{a}, \mathrm{b}}$ & $96.08 \%^{\mathrm{a}, \mathrm{b}}$ \\
$10 \%$ & 0.92 & 1.63 & $28.34^{\mathrm{b}}$ & $2.57^{\mathrm{b}}$ & $97.32 \% \%^{\mathrm{b}}$ \\
\hline
\end{tabular}

Because of the coalescence of pores and the semi-open pore structure, a simple pore area measurement would not give a true picture of the pore sizes, since that would treat multiple pores with even the slightest connection as a single large pore. In situations like these, the star volume is more appropriate, since it is less sensitive to interconnected pores. There was a clear trend regarding the star 
volume and the surface density (Table 1); where an increase in plasticizer content led to both an increase in star volume and a decrease in surface density. This in turn was a sign of coalescence; in low plasticizer content foams there were more but smaller pores, resulting in a high surface density. In foams made from resins with a higher plasticizer content, there were fewer but larger pores, and thus a greater star volume.

The display of coalescent behaviour is not in agreement with the strain-hardening properties at higher strain rates $\left(0.7 \mathrm{~s}^{-1}\right.$ and above, Fig. 4). The coalescence of expanding bubbles may be related to very low strain rates in the foams during foam formation. Another, perhaps more plausible, explanation is that the extensional viscosity of the resins was more important than the strain-hardening behaviour. It is probable that the decrease in extensional viscosity of the plasticized resins was too low for the pore walls to resist the strain of expanding bubbles. The cell walls therefore ruptured when the strain became too high, with gas leakage as a result. However, since the resin was heated from the outside inwards, the aqueous ethanol probably evaporated first from the periphery of the resin cylinder. The evaporation decreased the plasticization of the resin, and thus increased the extensional viscosity. In turn, this led to a greater gas-retaining capacity. Consequently, the foam structure was stabilized from the outside inwards. The $0 \%, 5 \%$ and $10 \%$ foams hence show a more regular structure near the edges than in the middle (Fig. 4). The foam from the $30 \%$ plasticizer resin was the extreme case; the gas expansion and the lack of cell wall resistance drove the resin towards the walls where it became stuck due to the higher temperature and consequent solvent evaporation. The product was just an empty cylindrical shell.

Since there was coalescence of pores even in the resin with the highest extensional viscosity, the upper limit of the extensional viscosity has probably not been reached. A reduction in extensional viscosity of the resins would probably yield foams with more regular structure and a narrower pore size distribution. The choice of $70 \%$ aqueous ethanol for resin forming was based on its use in zein film manufacturing for dissolving the protein. Experiments might identify another compound which is better for forming resins with a lower extensional viscosity and enhanced foaming properties.

\section{Density and mechanical properties}

The density was not significantly affected by the plasticizer concentration among the $0 \%, 5 \%$ and $10 \%$ plasticizer foams (Table 2). The pore size analysis show that the area located in large pores increased with increasing plasticizer content, which might suggest a decrease in density. As the area of large pores increased, however, the cell walls tended to increase in thickness, which leads to an increase in density. Therefore there was no net decrease in foam density. Compared to commercially available foams, the densities of these foams were rather high; expanded polystyrene foams (EPS) may have densities of 4.0 $-4.8 \mathrm{~g} / \mathrm{l}$, and starch-based foams may have densities as low as $4.8 \mathrm{~g} / \mathrm{l}^{21}$.

Table 2. Densities of foams from $0 \%, 5 \%$ and $10 \%$ resins. Values are not significantly different $(\mathrm{P}<0.05)$.

\begin{tabular}{lc}
\hline Sample & Density $(\mathrm{g} / \mathrm{l})$ \\
\hline $0 \%$ & 219,9 \\
$5 \%$ & 213,2 \\
$10 \%$ & 218,7 \\
\hline
\end{tabular}


Table 3. The fracture properties of the zein foams. Values are not significantly different $(\mathrm{P}<0.05)$.

\begin{tabular}{rcccc}
\hline & $\begin{array}{c}\text { Young's Modulus } \\
(\mathrm{MPa})\end{array}$ & $\begin{array}{c}\text { Absorbed Energy } \\
\left(\mathrm{kJ} / \mathrm{m}^{3}\right)\end{array}$ & $\begin{array}{c}\text { Stress at break } \\
(\mathrm{MPa})\end{array}$ & Strain at break \\
\hline $0 \%$ & 19.50 & 326.7 & 0.84 & $6.87 \%$ \\
$5 \%$ & 16.57 & 274.5 & 0.68 & $3.20 \%$ \\
$10 \%$ & 25.07 & 307.8 & 1.04 & $4.36 \%$ \\
\hline
\end{tabular}

Compressive testing showed insignificant differences in Young's modulus, absorbed energy, stress at break and strain at break (Table 3). Normally, it would be expected that the plasticizer content would affect the fracture mechanical properties by reducing the stress at break and increasing the strain at break. However, there were no significant signs of any such effect here. On the other hand, oleic acid seemed to have little the plasticizing effect on zein; Budi Santosa ${ }^{22}$ report that zein sheets containing $50 \%$ oleic acid merely show $7.5 \%$ strain at break, and e.g. Gillgren and Stading ${ }^{23}$ report a $115 \%$ strain at break for zein films plasticized with a polyethylene glycol/glycerol/lactic acid plasticizer mixture $(0.4 \mathrm{~g}$ plasticizer/g protein). These foams show approximately the same extensibility as the heavily plasticized zein sheets described by Budi Santosa ${ }^{22}$, but at far lower plasticizer contents. It can therefore be assumed that the structure has an impact on the tensile performance of the material. The plasticizing effect of oleic acid on the mechanical properties is probably minor compared to the contributions from the structure and the density. Of these two, density is plausibly the more prominent, since the foams showed significantly different structures, and the densities as well as the fracture properties were insignificantly different. As in the density case, the pore walls were probably thicker in the more plasticized samples. Because of this, and because there were only small variations in porous structure, it was expected that any variations with respect to mechanical properties among the zein foams would be insignificant. There are commercially available starch-based foams that are stronger (up to $30 \mathrm{MPa}$ ) as well as more extensible (up to $886 \%$ ). ${ }^{24}$ However, those have densities approximately six time those of the foams in this paper. EPS with approximately equivalent density (160 g/l) can have a stress at break $4.1-6.9$ $\mathrm{MPa}^{25}$, which is not much higher than the foams in the present investigation.

Resins with a higher gas retaining capacity than those presented in the current investigations would give foams with different qualities. Coalescence would decrease, giving a narrower pore size distribution as a result. It would probably be possible to produce foams with a lower density, since the cells walls would be better able to withstand the forces as the cells grew larger than those of the present foams. A different density and foam structure would also lead to different mechanical properties. Resins with a considerably lower extensional viscosity would probably have better gas retaining qualities and, since the lower extensional viscosity limit was not reached, it would be interesting to try to manufacture resins from a formula resulting in less plasticization.

\section{Conclusions}

A batch process, which can probably be up scaled for industrial purposes, was used to manufacture solid zein foams. Investigations show that rheological measurements can predict the foamability of a zein resin. This is probably also applicable to other resin-like materials, e.g. resins from other biopolymers. An increase in the plasticizer content in the resins led to coalescence of pores during foaming. This however, had no significant effect on the fracture mechanical properties of the foams. The mechanical properties of the foams were moderate compared to those of commercially available foams, both petroleum- and bio-based. On the other hand, there is a vast development potential in zein foams since these are first now being produced, while other foam materials have been developed for decades. For example, the manufacture and the use of additives are areas that could be explored. Potential 
applications of zein foams are as biodegradable food packages, as insulation, or as scaffolds for tissue engineering.

\section{Acknowledgements}

The Swedish Board of Agriculture and the Swedish Research Council for Environment, Agricultural Sciences and Spatial Planning, FORMAS, are gratefully acknowledged for financial support.

\section{References}

1 Lawton JW, Cereal Chem 79: 1-18 (2002)

2 Sun QS, Dong J, Lin ZX, Yang B, Wang JY, Biopolymers 78: 268-274 (2005)

3 Gong S, Wang H, Sun Q, Xue ST, Wang JY, Biomaterials 27: 3793-3799 (2006)

$4 \quad$ Dong J, Sun Q, Wang JY, Biomaterials 25: 4691-4697 (2004)

$5 \quad$ Wang HJ, Lin ZX, Liu XM, Sheng SY, Wang JY, J Controlled Release 105: 120-131 (2005)

$6 \quad$ Qu ZH, Wang HJ, Tang TT, Zhang XL, Wang JY, Dai KR, Acta Biomater 4: 1360-1368 (2008)

7 Kohn J, Abramson S, Langer R, Bioresorbable and Bioerodible Materials, in Biomaterials Science 2nd edition, ed by Ratner BD, Hoffman AS, Schoen FJ, Lemons JE. Elsevier Academic Press, London, pp 115-127 (2004).

8 Wang HJ, Gong SJ, Wang J-Y, Mater Sci Tech 24: 1045-1052 (2008)

$9 \quad$ Salerno A, Oliviero M, Di Maio E, Iannace S, Int Polym Proc 5: 480-488 (2007)

10 Dobraszczyk BJ, Roberts CA, J Cereal Sci 20: 265-274 (1994)

11 Gendron R, Rheological Behavior Relevant to Extrusion Foaming, in Thermoplastic Foam Processing: Principles Development, ed by Gendron R. CRC Press, Boca Raton, (2005).

12 Yamaguchi M, Melt Elasticity of Polyolefins: Impact of Elastic Properties on Foam Processing, in Polymeric Foams - Mechanisms and Materials, ed by Lee ST, Ramesh NS. CRC Press LLC, Boca Raton, (2004).

13 van Vliet T, J Cereal Sci 48: 1-9 (2008)

14 Oom A, Pettersson A, Taylor JRN, Stading M, J Cereal Sci 47: 109-116 (2008)

15 Wikström K, Bohlin L, J Cereal Sci 29: 217-226 (1999)

16 Stading M, Bohlin L, Ann Trans Nord Rheol Soc 8/9: 181-185 (2000)

17 Weibel ER, Elementary Introduction to Stereological Principles, in Stereological Methods, Academic Press, London, (1979).

18 Cruz-Orive LM, J Microsc 145: 121-142 (1987)

19 Andersson H, Öhgren C, Johansson D, Kniola M, Stading M, In press (2010)

20 Dobraszczyk BJ, Morgenstern MP, J Cereal Sci 38: 229-245 (2003)

21 Bohlmann GM, General Characteristics, Processability, Industrial Applications and Market Evolution of Biodegradable Polymers, in Handbook of Biodegradable Polymers, ed by Bastioli C. Rapra Technology Limited, Shropshire, (2005).

22 Budi Santosa FX, Padua GC, J Agric Food Chem 47: 2070-2074 (1999)

23 Gillgren T, Stading M, Food Biophys 3: 287-294 (2008)

24 Johnson M, The Economics and Market Potential for Low Environmental Impact Polymers, in Low Environmental Impact Polymers, ed by Tucker N, Johnson M. Rapra Technology Limited, Shropshire, (2004).

25 Suh KW and Tusim MH, Foam Plastics, in The Wiley Encyclopedia of Packaging Technology 2nd edition, ed by Brody AL, Marsh KS. John Wiley \& Sons, Inc., New York, pp 451-458 (1997). 